\title{
MICROSTRUCTURAL EVOLUTION AND MECHANICAL PROPERTIES OF ULTRA-LOW CARBON STEEL AFTER SEVERE PLASTIC DEFORMATION PROCESS
}

\author{
${ }^{1}$ Magdalena JABŁOŃSKA, ${ }^{1}$ Karolina KOWALCZYK, ${ }^{2}$ Stanislav RUSZ, ${ }^{1}$ Iwona BEDNARCZYK \\ ${ }^{1}$ VSB - Technical University of Ostrava, Ostrava, Czech Republic, EU, stanislav.rusz@vsb.cz \\ 2Silesian University of Technology, Katowice, Poland, EU, magdalena.jablonska@polsl.pl \\ https://doi.org/10.37904/metal.2019.699
}

\begin{abstract}
This article presents the impact of continuous plastic deformation SPD with the DRECE technique on a structure and properties of low carbon IF steel. The impact of numbers of passes on a change of mechanical properties of tested steel, such as tensile strength TS and yield strength YS, was tested. Within the SPD techniques an unconventional method of deformation was used, which is DRECE - Dual Rolls Equal Channel Extrusion developed on VŠB - Technical University in Ostrava. This technique uses reproducible plastic deformation to refine the structure and improve the mechanical properties of a metal band [1]. Numerous changes in the structure and they were associated to evolution of a dislocation structure and grain refinement were observed. In the case of the tested steel the increase of resistance properties was confirmed after the DRECE process after first pass through the device. The biggest hardening of the material is observed after the fourth pass
\end{abstract}

Keywords: SPD process, interstisial free steel, microstructure, mechanical properties

\section{INTRODUCTION}

A significant increase of interest in construction materials with strongly refinement structures can be observed in recent years [2-5]. The increasing requirements which modern materials must met have enforced improvement of manufacturing processes in order to obtain high mechanical properties [5-7]. The most widespread methods of producing materials with nano-grained and ultra-fine-grained structure include, among others, methods using accumulation of severe plastic deformation SPD and special processes of thermal and plastic processing ATP (Advanced Thermo mechanical Processing). SPD processes are defined as plastic forming processes using the accumulation of severe plastic deformation that is necessary to refine the structure while maintaining cohesion of deformed material. These processes are held at ambient temperature or under hot forming [6-7]. The best-known SPD methods are:

- $\quad$ ECAP (Equal Channel Angular Pressing),

- HPT (High Pressure Torsion),

- $\quad$ ARB (Accumulative Roll Bonding),

- $\quad$ CEC (Cyclic Extrusion Compression),

- $\quad \mathrm{MC}$ (Multiaxial Compression),

- $\quad \mathrm{KOBO}$ method (its name comes from combined names of its creators - Korbel and Bochniak).

Despite the growing interest in the severe plastic deformation methods in recent years the efforts have been made to develop new unconventional SPD techniques. These techniques include: DCAP (Dissimilar Channel Angular Pressing), AARB (Asymmetrical Accumulative Roll Bonding) and DRECE (Dual Rolls Equal Channel Extrusion). They allow to deform construction materials with much bigger dimensions than the ones, which are present in the classical SPD methods and they increase the homogeneity of the obtained structure [1,5,8-11]. The DRECE method (Figure 1) was developed on the basis of DCAP and ECAP - CONFORM (Continuous Forming) methods and is intended to shape metal sheets or bands with maximal dimensions of $1000 \times 60 \times 2$ $\mathrm{mm}$. The material is introduced into the working area and then pressed with press rolls through forming tool 
without changing its cross section. Multiple plastic deformation carried out this way impacts changes of the structure and mechanical properties in relation to the initial material. The factor determining the increase of mechanical properties of the material after extrusion in the DRECE process is the selection of the optimal forming angle in the plastic area $\left(123^{\circ}, 118^{\circ}\right.$ or $\left.108^{\circ}\right)$ that is determined by the structural arrangement of the forming tool and the number of passes through the device [1].

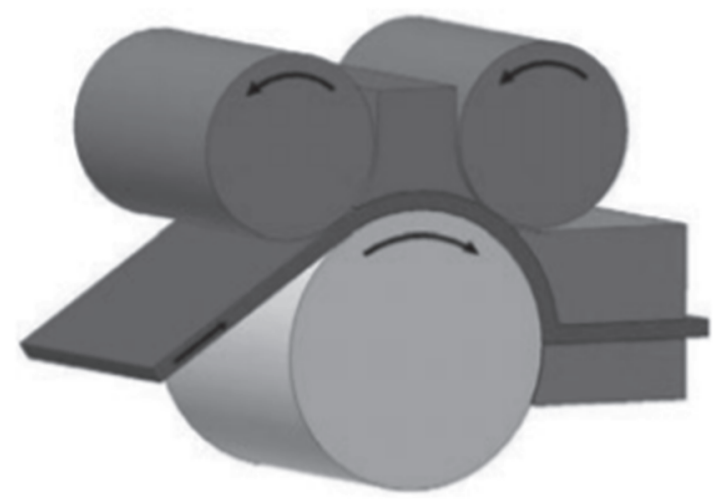

Figure 1 Scheme of a DRECE process [1]

A particularly attractive research material for the development of new technologies for the production of ultrafine materials are low-carbon and microalloyed steels [2]. Lower production costs related to expensive alloy additions, minimization or elimination of heat treatment after hot deformation, improvement of weldability that is a result of low content of carbon and alloy elements - these are the benefits of structure refinement in the case of conventional steels usage. Increasing of mechanical properties while maintaining good plastic properties may broaden potential use of low carbon steels not only in the automotive industry but also in new areas, e.g. in the aviation and arms industry [2,10,12].

This article presents the results of tests of the structure and properties of low carbon steel shaped in an unconventional SPD process - DRECE.

\section{EXPERIMENTAL PROCEDURE}

The material for researches was a metal band of low carbon IF steel after annealing in the temperature of $850^{\circ} \mathrm{C} / 25 \mathrm{~min}$ (Figure 2). The conducted heat treatment has allowed to remove structural effect resulting from previous technological treatments [13]. IF steel is characterized by a single-phase ferritic structure and does not contain interstitial elements in the solid solution.Due to low content of carbon it has good plastic properties. The chemical composition of tested steel is presented in Table 1.
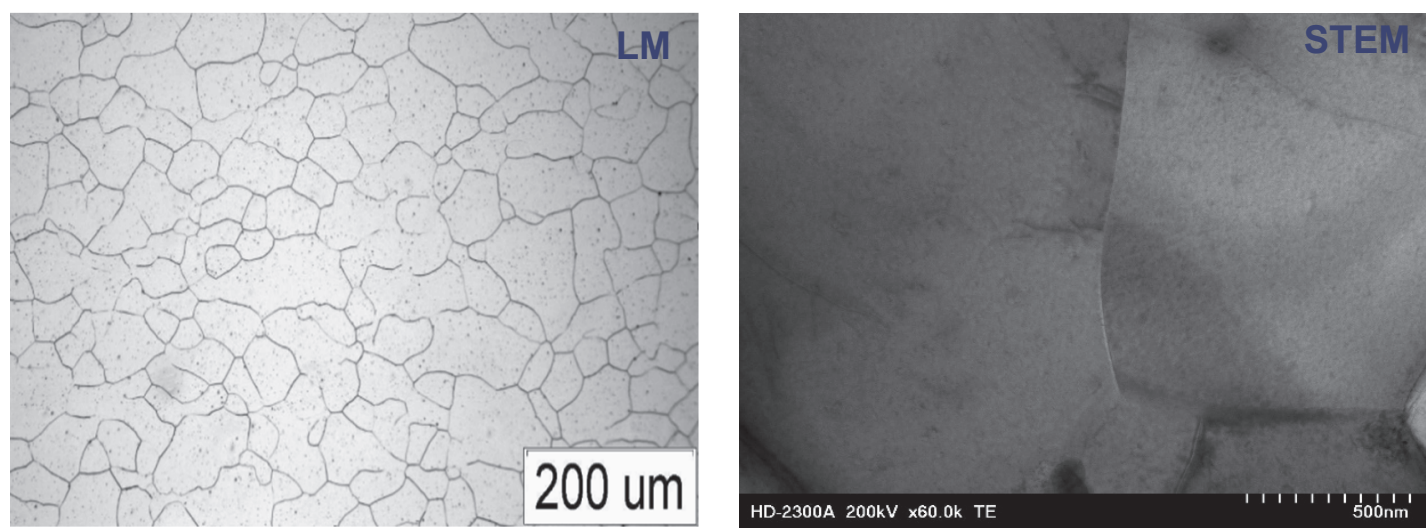

Figure 2 Microstructure of IF steel after annealing 
Table 1 The chemical composition of low carbon steel wt.\%

\begin{tabular}{|c|c|c|c|c|c|c|c|c|}
\hline $\mathbf{C}$ & $\mathbf{M n}$ & $\mathbf{S i}$ & $\mathbf{C r}$ & $\mathbf{N}$ & $\mathbf{C u}$ & $\mathbf{A l}$ & $\mathbf{T i}$ & $\mathbf{P}$ \\
\hline 0.002 & 0.12 & $<0.005$ & 0.019 & 0.005 & 0.02 & 0.029 & 0.059 & $<0.009$ \\
\hline
\end{tabular}

SPD tests with unconventional DRECE methods were held on VŠB - Technical University in Ostrava, Department of Mechanical Engineering, $\alpha$ angle in the deformation zone was $108^{\circ}$. Metal sheets with dimension of $8000 \times 40 \times 2 \mathrm{~mm}$ were the load. There were 8 passes and every next pass was held without changing position toward the initial position after the first pass.

Before every pass through the DRECE device the surface of the sheet was covered with Gleit lubricant - $\mu$ HP 515 used to reduce friction between the tool and the tested material. The pressure on the introductory roll was 150 bar and on the press rolls (before the deformation area) 30 bar. The rate of pass of the material through the DRECE device was $40 \mathrm{~mm} / \mathrm{min}$.

Change of mechanical properties after the plastic deformation process on mechanical properties of bands was tested in static tensile test. Tests were held on series of three specimens with standard tensile testing machine ZWICK with maximum force of $100 \mathrm{kN}$ according to PN-EN ISO 6892-1:2010. Specimens with rectangular section were used (Figure 3). Every specimen was taken from an area placed parallel to the direction of deformation.
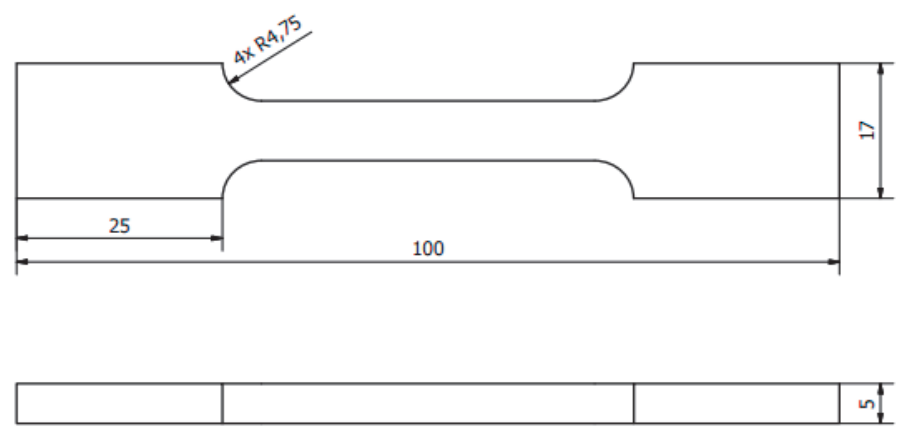

Figure 3 Dimensions of specimens after the static tensile test, dimensions in the unit $\mathrm{mm}$

Researches of the structure were held on specimens in the form of thin films with usage of scanning transmission electron microscopy STEM. A microscope HITACHI HD-2300A equipped with FEG gun working at accelerating voltage of $200 \mathrm{kV}$.

\section{RESULTS AND DISCUSSION}

The macrostructure of the tested steel is presented in Figures $4 \mathrm{a}-\mathrm{h}$. After the first pass changes related to the evolution of dislocation structure in the form of increase of density of dislocations and many dislocation tangles can be noted (Figures $4 \mathbf{a}-\mathbf{b}$ ). Cellular dislocation systems as well as dislocation walls DDWs are visible. Grain is divided into smaller volumes and a result of it is generation of dislocation boundaries of LABs type (Figure 4b). After the fourth pass the characteristic convexity of the HABs boundaries can be observed (Figure 4c) and they are not the effect of migration of the boundaries but their mutual crossing. That means that the formation of ultra-fine-grained structures is not determined by the recrystallization process. Dislocations loops inside grains and grains with high density of dislocations in the area of the boundaries are visible (Figure 4d). Lamellar boundaries of LBs with different distances between them form themselves. Finegrained structure is shaped. The boundaries of the high angle establish themselves (Figures $4 \mathrm{e}-\mathrm{f}$ ). After the eighth pass through the DRECE ordering of the dislocation structure and the creation of dislocated polygonal walls are observed (Figure $\mathbf{4 g}$ ). There occur processes of recovery and formation of new grains free of dislocations (Figure $\mathbf{4 h}$ ). It does not favor the further grain refinement. 

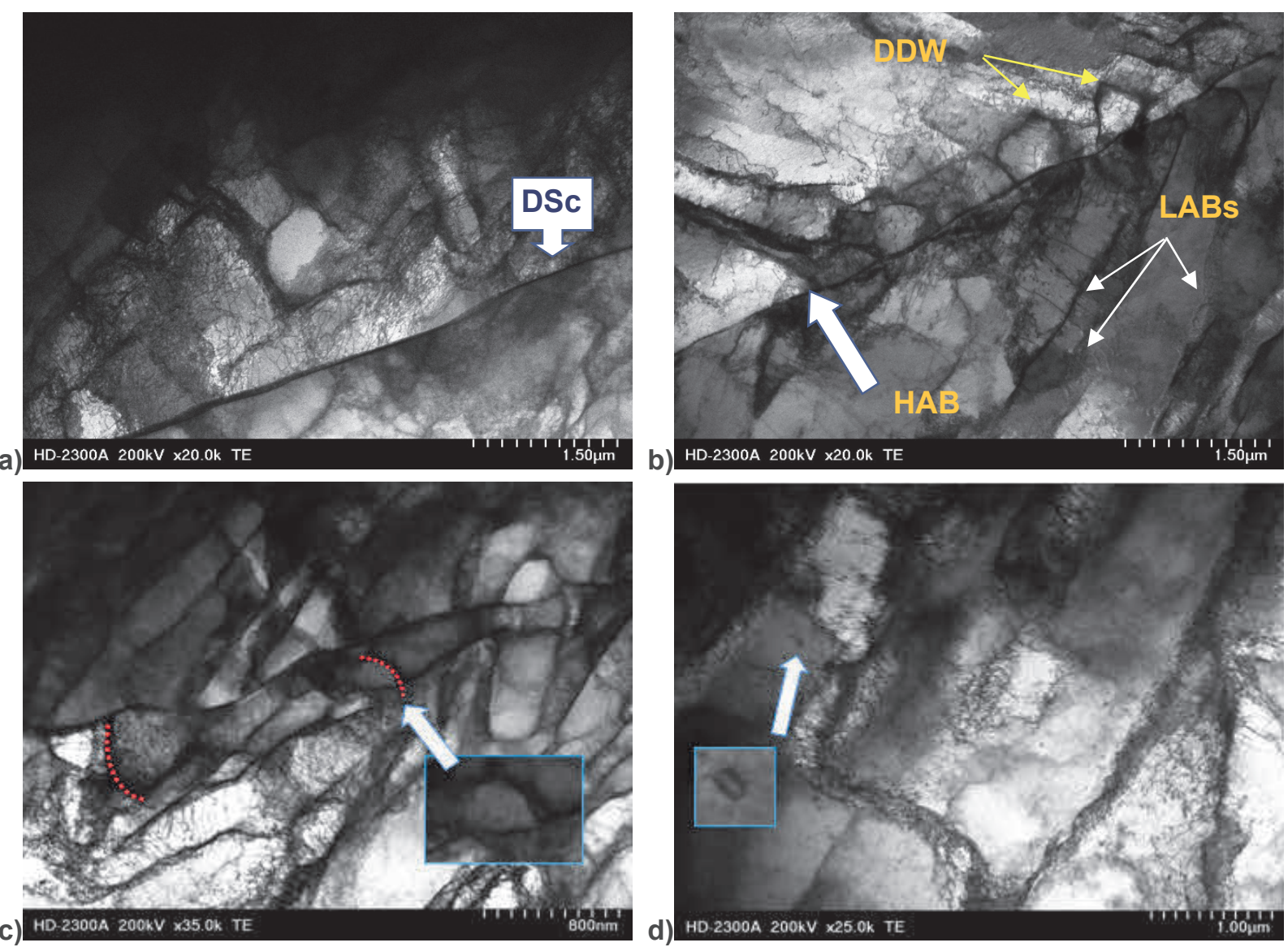

c)

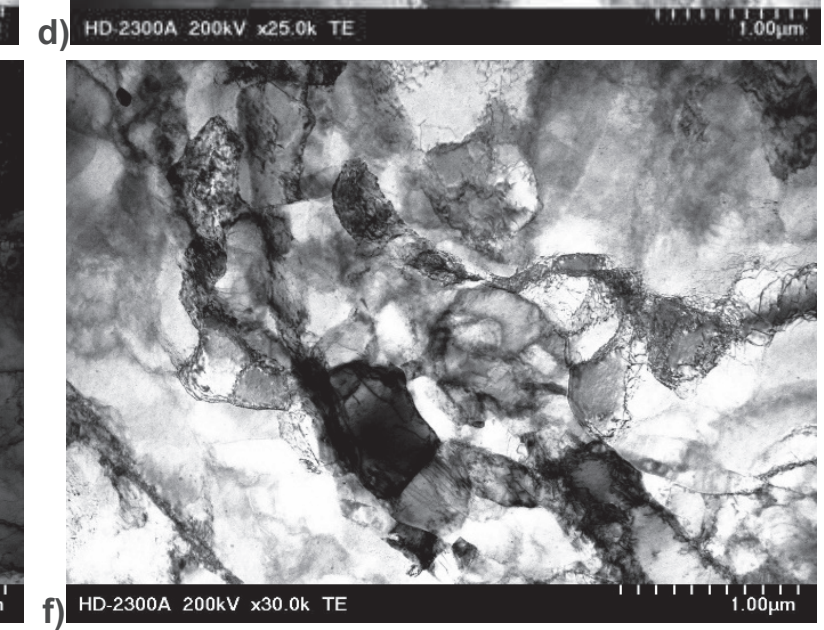

e)
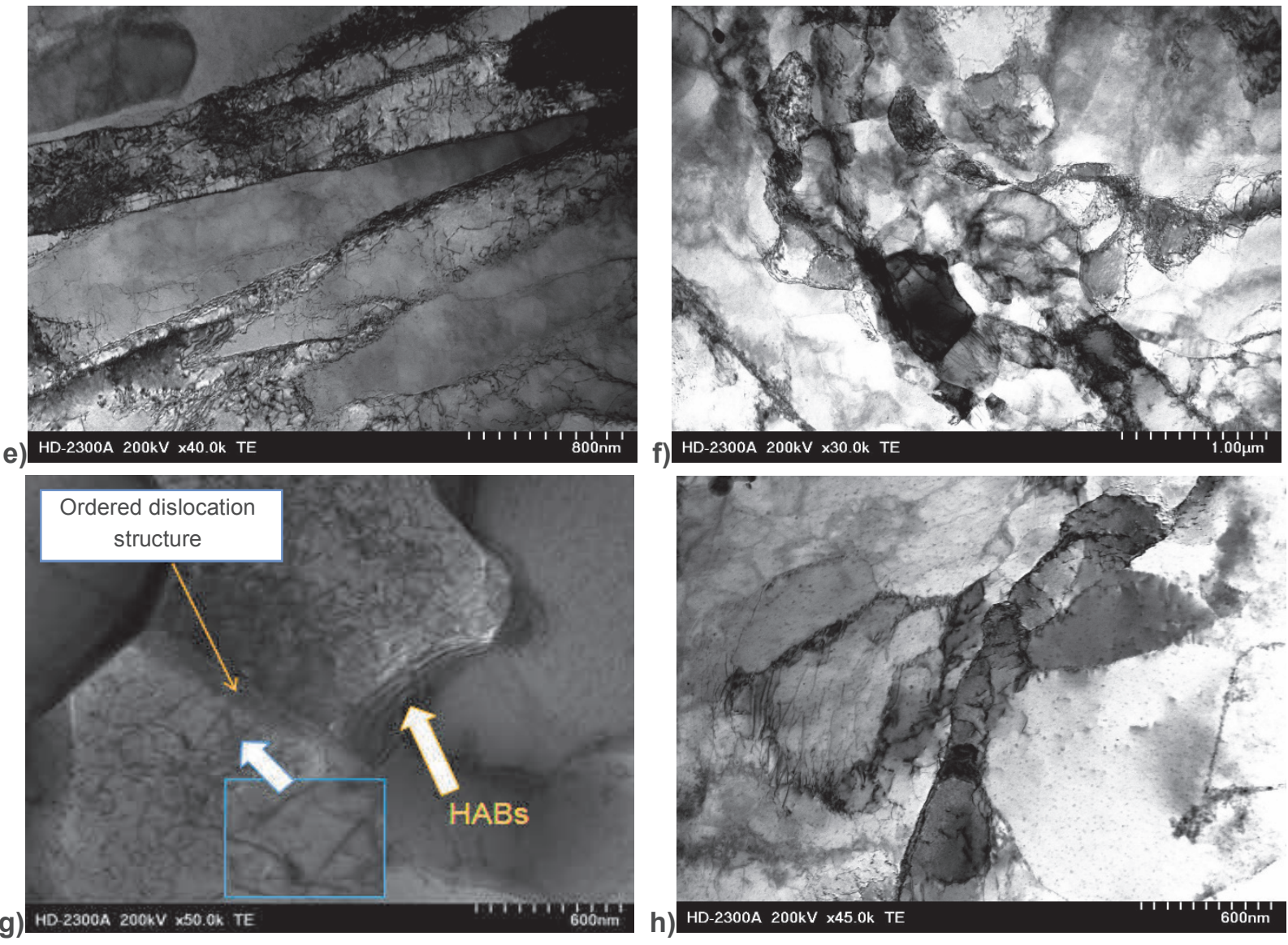

Figure 4 Microstructure of IF steel after $1^{\text {st }}$ pass $(a-b), 4^{\text {th }}$ pass $(c-f)$ and 8 th pass $(g-h)$ 
The obtained results of mechanical properties of low carbon steel after the deformation with the DRECE method are presented in Figure $\mathbf{5}$ and on the Table 2. In the result of used deformation, the tensile strength has increased after the first pass to $295 \mathrm{MPa}$.After the fourth pass steel achieves TS equal to $385 \mathrm{MPa}$ and it means that there has been $30 \%$ increase of tensile strength in relation to the initial material. The yield strength YS for steel in the initial state was $121 \mathrm{MPa}$. After the first pass it increases to $276 \mathrm{MPa}$ and after the 4th to $326 \mathrm{MPa}$. Further increasing number of passes has not resulted in a significant increase in mechanical properties. Steel in the initial state is characterized by good plastic properties. Elongation $A_{5}$ reaches $55 \%$ and necking level is $65 \%$, however, along with the increase of number of passes a sharp drop in the ductility of the material was noticed. The value of the necking $Z$ changes slightly with subsequent passes through the DRECE device. The highest value of necking is observed with the lowest value of YS/TS. Such behavior of the material after the SPD process is characteristic for most low carbon steels.

Table 2 Elongation, necking, tensile strength, yield stress and value of the reserve of plasticity of IF steel after the static tensile test

\begin{tabular}{|c|c|c|c|c|c|}
\hline $\begin{array}{c}\text { Number of } \\
\text { passes, } \boldsymbol{\alpha}=\mathbf{1 0 8}^{\circ}\end{array}$ & TS & YS & A5 (\%) & Z (\%) & YS/TS \\
\hline Initial state & 268 & 121 & 55 & 65 & 0.45 \\
\hline $1 \mathrm{x}$ & 296 & 274 & 29 & 60 & 0.93 \\
\hline $4 \mathrm{x}$ & 349 & 326 & 14 & 61 & 0.93 \\
\hline $8 \mathrm{x}$ & 338 & 319 & 61 & 58 & 0.94 \\
\hline
\end{tabular}

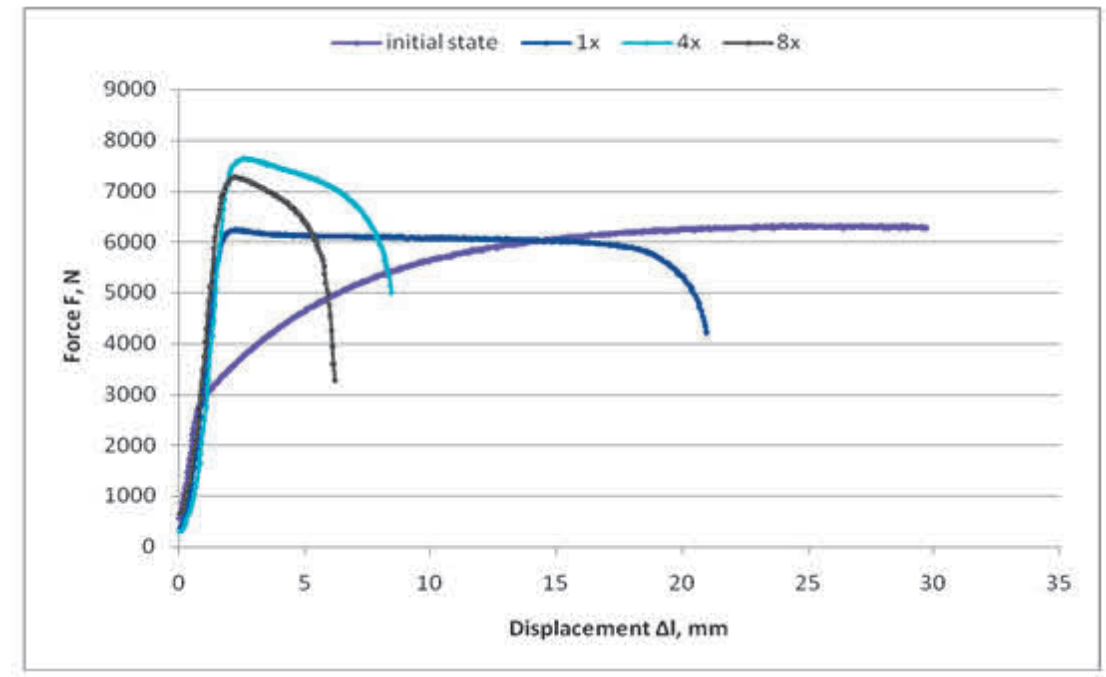

Figure 5 Tensile test diagram for IF steel

\section{CONCLUSIONS}

The presented results show a positive effect of SPD plastic deformation process with the DRECE technique on the mechanical properties and refinement of the structure of tested low carbon steel. The refinement of the structure occurs as a result of dislocation boundaries generation that in subsequent stages transform into an ultra-fine-grained structure. Sometimes accumulated dislocations create polygonal systems. Within areas separated by lamellar borders there are areas with an ordered dislocation structure. Strength characteristics confirm significant improvement of mechanical properties after the DRECE process in relation to the initial material. The highest value of TS and YS is observed after the 4th pass. Grain refinement is related to drop of 
plastic properties. The limited ductility in ultra-fine-grained materials is associated with the phenomenon of early plastic instability, which results, among others, from the heterogeneity of the obtained structure.

\section{REFERENCES}

[1] RUSZ S., MALANIK M., DUTKIEWICZ J., ČIZEK L., DONIČ T., KEDRON J., TYLSAR S. New design of the forming equipment DRECE for obtaining UFG structure in strip of sheet, Archives of Materials Science and Engineering, 2010, vol. 42, pp. 111-118.

[2] TAMIMI S., KETABCHI M., PARVIN N. Microstructural evolution and mechanical properties of accumulative roll bonded interstitial free steel, Materials and Design, 2009, vol. 30, pp. 2556-2562.

[3] KURZYDŁOWSKI K. J., Microstructural refinement and properties of metals processed by severe plastic deformation, Bulletin of the Polish Academy of Sciences, Technical Sciences, 2004, vol. 52, pp. 301-311.

[4] LESZCZYŃSKA-MADEJ P., PAŁKA M., RICHERT M. Effect of severe plastic deformation on microstructure and properties of polycrystalline aluminum Al99,5 - wpływ intensywnych odkształceń plastycznych na zmiany mikrostruktury i właściwości polikrystalicznego aluminium Al99,5, Archives of Metallurgy and Materials, vol. 59, 2014, pp. 313-316.

[5] LEWANDOWSKA M., KURZYDŁOWSKI K. J. Recent development in grain refinement by hydrostatic extrusion, Journal of Materials Science, vol. 43, 2008, pp. 7299-7306.

[6] RODAK K., URBAŃCZYK-GUCWA A., JABŁOŃSKA M., PAWLICKI J., MIZERA J. formation of ultrafine-grained structure of Al-Li alloys processed by SPD Archives of Civil and Mechanical Engineering, vol. 18, 2018, pp. 331337.

[7] KRAWCZYŃSKA A., CHROMIŃSKI W., URA-BIŃCZYK E., KULCZYK M., LEWANDOWSKA M. Mechanical properties and corrosion resistance of ultrafine grained austenitic stainless steel processed by hydrostatic extrusion, Materials \& Design, vol. 136, 2017, pp. 34-44.

[8] LANGDON T. G. The principles of grain refinement in equal-channel angular pressing, Materials Science and Engineering, 2007, vol. 462, pp. 3-11

[9] BOCHNIAK W. Teoretyczne i praktyczne aspekty plastycznego ksztaltowania metali, metoda KOBO, Wydawnictwa AGH, 2009, Karków.

[10] LEE S.H., UTSUNOMIYA H., SAKAI T. Microstructures and mechanical properties of ultra low carbon interstitial free steel severely deformed by a multi-stack Accumulative Roll Bonding Process, Materials Transactions, vol. 45, 2004, pp. 2177-2181.

[11] RODAK K., PAWLICKI J., TKOCZ M. Deformation-Induced Grain Refinement in AIMg5 Alloy, Solid State Phenomena, vol. 191, 2012, pp. 37-44.

[12] EDDAHBI M., RAUCH E.F. Texture and microstructure of ultra low carbon steel processed by equal channel angularextrusion, Materials Science Engineering 2009, vol. 502, pp. 13-24.

[13] KOWALCZYK K., JABŁOŃSKA M., RUSZ S., JUNAK G. Influence of recrystallization on the properties and structure of low-carbon ferritic steel IF, Archives of Metallurgy and Materials, 2018, vol. 63 pp. 1955-1959. 